INRA Prod. Anim.,

2013, $26(5), 403-414$

\title{
| La stéatose hépatique chez les palmipèdes
}

\author{
E. BAÉZA I, C. MARIE-ETANCELIN ${ }^{2}$, S. DAVAIL ${ }^{3}$, C. DIOT ${ }^{4,5}$ \\ ${ }^{1}$ INRA, UR83 Recherches Avicoles, F-37380 Nouzilly, France \\ 2 INRA, UR631 SAGA, F-31326 Castanet-Tolosan, France \\ ${ }^{3}$ IUT des Pays de l'Adour, UMRCNRS 5254 IPREM - EEM, F-40004 Mont-de-Marsan, France \\ ${ }^{4}$ INRA, UMR1348 PEGASE, F-35590 Saint-Gilles, France \\ 5 Agrocampus Ouest, UMR1348 PEGASE, F-35000 Rennes, France \\ Courriel : Elisabeth.Baeza@tours.inra.fr
}

Seules quelques espèces d'oies et de canards sont utilisées pour la production de foie gras. Quelles sont les particularités physiologiques et métaboliques de ces animaux qui leur confèrent cette aptitude à développer une stéatose hépatique lors du gavage ? Sur la base des connaissances actuelles, est-il encore possible d'optimiser la production de foie gras ?

La stéatose hépatique est caractérisée par une accumulation de triglycérides dans les hépatocytes. Chez les animaux sauvages, l'accumulation de lipides au niveau du foie est une adaptation physiologique aux besoins énergétiques dans des situations bien particulières comme la migration et l'hibernation. Chez certains palmipèdes, cette aptitude à la stéatose hépatique est exploitée depuis plus de 4500 ans pour produire des oiseaux engraissés et du foie gras (Pingel et al 2012). La production actuelle de foie gras est confrontée à plusieurs contraintes économiques et règlementaires. Elle est très coûteuse sur le plan alimentaire. Il faut environ $10 \mathrm{~kg}$ de maïs pour produire un foie gras de canard de $550 \mathrm{~g}$. Le gavage doit être à la fois de courte durée mais intense, afin d'obtenir un foie gras de taille commercialisable (poids supérieur à $300 \mathrm{~g}$ pour le canard) et de bonne qualité sanitaire, sensorielle et technologique (absence de défauts visuels, texture ferme, faible taux de fonte à la cuisson). Enfin, la production de foie gras doit prendre en compte la réglementation concernant le bien-être des animaux. La maîtrise de ces différents aspects repose sur une optimisation des conditions d'élevage et de gavage, mais également des aptitudes intrinsèques des animaux à l'engraissement et en particulier de leur métabolisme lipidique. Si les phénomènes de stéatose hépatique sont assez répandus chez les oiseaux comme la poule pondeuse, l'aptitude à produire un foie gras après 12 jours de gavage n'est pas le fait de toutes les espèces. Après avoir rappelé les bases physiologiques et métaboliques du développement de la stéatose hépatique chez les palmipèdes, nous présenterons l'état actuel des connaissances sur le déterminisme de l'aptitude à la stéatose hépatique chez les oies et les canards. Enfin, le gavage étant considéré comme une alimentation forcée, des travaux ont été entrepris pour évaluer les possibilités de surconsommation spontanée d'aliment favorisant le développement d'une stéatose hépatique sans pratique du gavage. Les premiers résultats obtenus dans ce domaine chez l'oie seront présentés.

\section{1 / Bases physiologiques et métaboliques du développe- ment de la stéatose hépatique chez les palmipèdes}

Le foie gras des palmipèdes gavés résulte d'une stéatose hépatique d'origine nutritionnelle, hypertrophique et réversible. Cette stéatose est intense puisque, chez l'oie, le poids de foie peut être multiplié par 10 en 15 jours, passant de $100 \mathrm{~g}$ à $1 \mathrm{~kg}$ représentant ainsi jusqu'à $10 \%$ du poids corporel (Hermier et al 1999a).

\section{1 / Particularités du métabo- lisme lipidique des oiseaux}

Chez les oiseaux, les lipides alimentaires, après leur absorption dans l'intestin grêle, sont assemblés dans les entérocytes sous forme de portomicrons (équivalents aux chylomicrons des mammifères) et libérés dans la circulation porte. Les portomicrons vont donc être captés en partie par le foie avant de rejoindre la circulation générale. Ainsi, les lipides qu'ils transportent vont pouvoir être utilisés par le foie dès ce premier passage. C'est le cas en particulier des acides gras polyinsaturés essentiels dont la teneur dans l'aliment de gavage est élevée. En effet, l'acide linoléique (C18:2 n-6) représente environ 53\% des acides gras totaux du maïs.

Chez les oiseaux, le foie est le site principal de la lipogenèse de novo (Léveille et al 1975). Comme chez les mammifères, la synthèse des acides gras dépend de la disponibilité de précurseurs glucidiques alimentaires. Elle est donc fortement stimulée en période de gavage car le maïs est riche en amidon et la quantité de maïs distribuée par repas est élevée passant de $300 \mathrm{~g}$ en début de gavage à $600-700 \mathrm{~g}$ en fin de gavage selon la courbe appliquée. En tenant compte des teneurs respectives en amidon (environ $70 \%$ ) et en lipides (environ 4\%) du maïs et de la capacité de conversion de l'acide linoléique et du glucose en lipides neutres par le foie (Saez et al 2008), la part des triglycérides stockés dans le foie provenant des glucides alimentaires peut être estimée à $90 \%$. Les lipides hépatiques (triglycérides, phospholipides et cholestérol) sont assemblés dans le foie et exportés sous forme de lipoprotéines dans la circulation sanguine. Les triglycérides s'associent préférentiellement à l'apolipoprotéine B (apo B) pour former des VLDL ( Very Low Density Lipoproteins ») tandis que la majorité du cholestérol et des phospholipides s'associent à l'apolipoprotéine A-I pour former des HDL ( $"$ High Density Lipoproteins »). Les VLDL sont ensuite hydrolysées grâce à la lipoprotéine lipase afin de permettre le captage des acides gras par les tissus périphériques musculaires et adipeux. La lipogenèse étant très limitée dans le tissu adipeux des oiseaux (Léveille et al 1975), la croissance de ce tissu dépend essentiellement du captage et de la ré-estérification des acides gras apportés par les VLDL. La 
totalité des lipides secrétés par le foie n'est pas déposée dans les tissus périphériques et une fraction retourne au foie accentuant ainsi le développement de la stéatose hépatique. A notre connaissance, l'importance de cette fraction et sa variation éventuelle entre espèces et au cours du gavage n'a jamais été quantifiée.

\section{2 / Effets du gavage sur le métabolisme hépatique}

L'aliment de gavage est très énergétique (3 $250 \mathrm{kcal} / \mathrm{kg})$, riche en glucides mais pauvre en lipides $(4 \%)$ et en protéines (8 à 11\%). Ce type d'aliment stimule fortement la lipogenèse hépatique et la production de lipoprotéines hépatiques. De plus, le ratio énergie/protéines est très déséquilibré ce qui favorise aussi, chez les oiseaux, la synthèse de lipides. Une des fonctions métaboliques du foie est de maintenir l'homéostasie glucidique.
Le glucose en excès est donc converti en acides gras via la conversion de glucose en pyruvate qui entre dans le cycle de Krebs des mitochondries des hépatocytes (Browning et Horton 2004, figure 1). Le citrate produit par le cycle de Krebs est transporté dans le cytosol où il est converti en acétyl-CoA par l'ATP Citrate LYase (ACLY). L'Acétyl-CoA Carboxylase 1 (ACC1) convertit ensuite l'acétyl-CoA en malonyl-CoA qui est utilisée par la "Fatty Acid Synthase » (FAS) pour produire de l'acide palmitique (C16:0). Ce dernier est alors soit désaturé par la Stéaroyl-CoA Désaturase (SCD) en acide palmitoléique (C16:1), soit allongé grâce à la « long chain fatty acyl elongase » pour produire de l'acide stéarique $(\mathrm{C} 18: 0)$ qui peut aussi être, à son tour, désaturé pour former de l'acide oléique (C18:1). Ces différents acides gras sont ensuite utilisés pour la synthèse des triglycérides. Cette synthèse de novo des acides gras dans le foie est régulée de façon indépendante par l'insuline et le glucose (Browning et Horton 2004). L'action de l'insuline est modulée par le facteur de transcription « Sterol Regulatory Element-Binding Protein-1c » (SREBP1c). Dans le noyau, SREBP-1c active tous les gènes des enzymes impliquées dans la lipogenèse en particulier l'acétyl-CoA Carboxylase 2 (ACC2) qui produit du malonyl-CoA au niveau des membranes mitochondriales. Or, le malonyl-CoA inhibe l'activité de la Carnitine Palmitoyl Transferase-1 (CPT-1), ce qui a pour effet de diminuer l'oxydation des acides gras dans la mitochondrie. L'action du glucose est modulée par le facteur de transcription «Carbohydrate Response Element Binding Protein » (ChREBP) qui stimule en particulier la synthèse de Pyruvate Kinase (PK) catalysant la conversion de phosphoenolpyruvate en pyruvate. ChREBP régule donc la glycolyse et la lipogenèse (figure 1).

Figure 1. Mécanismes de la stéatose hépatique.

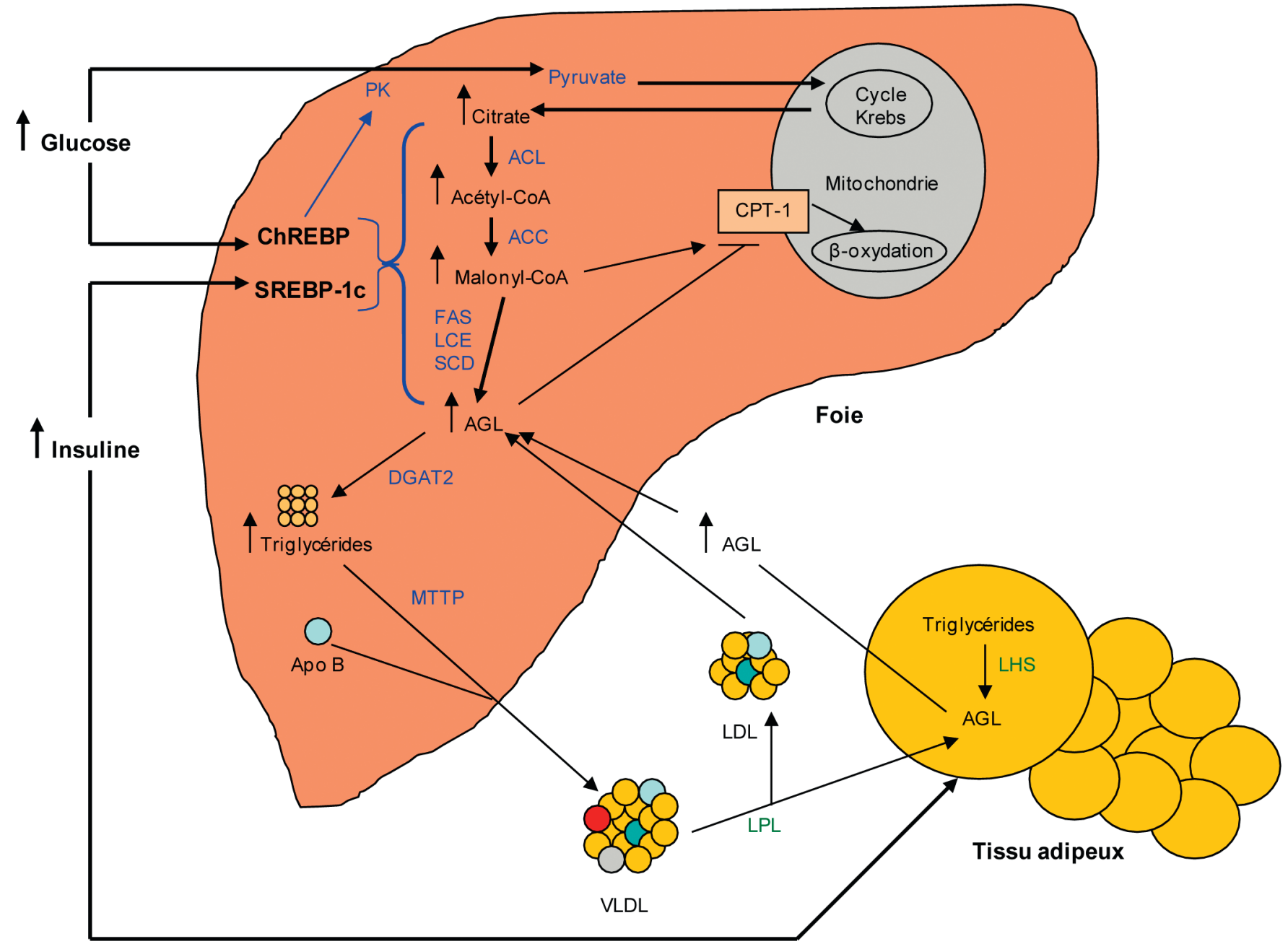

PK : Pyruvate Kinase ; ACL : ATP Citrate Lyase ; ACC : Acétyl-CoA Carboxylase ; FAS : Fatty Acid Synthase ; LCE : Long-Chain Fatty Acyl Elongase ; SCD : Stearoyl-Coa Desaturase; AGL : Acides Gras Libres ; VLDL : Very Low Density Lipoproteins ; LDL : Low Density Lipoproteins; CPT-1: Carnitine Palmitoyl Transferase ; LHS: Lipase Hormono-Sensible ; LPL: Lipoproteine Lipase ; ChREBP : Carbohydrate Response Element Binding-Protein ; SREBP-1c : Sterol Regulatory ElementBinding Protein-1c ; MTTP : Microsomal Triglyceride Transfer Protein ; DGAT2 : DiacylGlycerol O-AcylTransferase 2. 
Tableau 1. Effet du gavage sur l'activité (UI/mg protéines) d'enzymes de la lipogenèse dans le foie de canards de Barbarie ou mulards âgés de 14 semaines, nourris à volonté ou gavés pendant 14 jours et sacrifiés plus de 12 heures après leur dernier repas (moyenne $\pm E T, n=8$, Chartrin et al 2006a).

\begin{tabular}{|l|c|c|c|c|}
\hline \multirow{2}{*}{} & \multicolumn{2}{|c|}{ Barbarie } & \multicolumn{2}{c|}{ Mulard } \\
\cline { 2 - 5 } & Maigre & Gavé & Maigre & Gavé \\
\hline Acétyl CoA carboxylase & $0,37 \pm 0,22^{\mathrm{b}}$ & $2,24 \pm 0,90^{\mathrm{a}}$ & $0,34 \pm 0,13^{\mathrm{b}}$ & $1,70 \pm 1,11^{\mathrm{a}}$ \\
\hline Enzyme malique & $1,29 \pm 0,28^{\mathrm{b}}$ & $5,44 \pm 1,04^{\mathrm{a}}$ & $1,37 \pm 0,38^{\mathrm{b}}$ & $5,21 \pm 1,69^{\mathrm{a}}$ \\
\hline Glucose-6-phosphate déshydrogénase & $1,06 \pm 0,22^{\mathrm{b}}$ & $2,00 \pm 0,54^{\mathrm{a}}$ & $1,75 \pm 0,90^{\mathrm{b}}$ & $3,11 \pm 0,69^{\mathrm{a}}$ \\
\hline
\end{tabular}

$a, b$ : effet significatif du gavage à $P<0,001$.

Tableau 2. Effet du gavage sur les lipides circulants (mmol/l), l'insulinémie $(\mu U / \mathrm{ml})$ et la glycémie ( $\mathrm{g} / \mathrm{l})$ ) de canards de Barbarie ou mulards âgés de 14 semaines, nourris à volonté ou gavés pendant 14 jours et sacrifiés plus de 12 heures après leur dernier repas (moyenne $\pm E T, n=8$, Baéza et al 2005).

\begin{tabular}{|l|c|c|c|c|}
\hline \multirow{2}{*}{} & \multicolumn{2}{|c|}{ Barbarie } & \multicolumn{2}{c|}{ Mulard } \\
\cline { 2 - 5 } & Maigre & Gavé & Maigre & $5,15 \pm 1,15^{\mathrm{a}}$ \\
\hline Phospholipides & $2,76 \pm 0,54^{\mathrm{b}}$ & $4,98 \pm 1,02^{\mathrm{a}}$ & $4,12 \pm 0,41^{\mathrm{b}}$ & $2,98 \pm 0,89^{\mathrm{a}}$ \\
\hline Triglycérides & $0,85 \pm 0,27^{\mathrm{b}}$ & $2,42 \pm 0,82^{\mathrm{a}}$ & $1,37 \pm 0,39^{\mathrm{b}}$ & $6,23 \pm 1,51^{\mathrm{a}}$ \\
\hline Cholestérol total & $3,85 \pm 0,63^{\mathrm{b}}$ & $5,86 \pm 0,92^{\mathrm{a}}$ & $5,18 \pm 0,66^{\mathrm{b}}$ & $14,4 \pm 2,0^{\mathrm{a}}$ \\
\hline Insulinémie & $8,8 \pm 1,3^{\mathrm{b}}$ & $12,7 \pm 2,0^{\mathrm{a}}$ & $6,5 \pm 0,9^{\mathrm{b}}$ & $1,62 \pm 0,14$ \\
\hline Glycémie & $1,78 \pm 0,70$ & $1,87 \pm 0,24$ & $1,56 \pm 0,14$ & 14 \\
\hline
\end{tabular}

a, b : effet significatif du gavage à $P<0,001$.

Chez des canards en fin de gavage, Hérault et al (2010) ont bien montré une surexpression, dans le foie, de plusieurs gènes impliqués dans la lipogenèse tels que DGAT2, SCD, ACLY, ChREBP, FAS et SREBP-1 et une sous-expression des gènes codant pour l'apo $B$ et pour CPT-1, suggérant une augmentation de la synthèse des acides gras et des triglycérides et une diminution de la formation des VLDL et de l'oxydation des acides gras favorisant l'accumulation de triglycérides dans le foie. En revanche, l'expression de PPAR- $\gamma$, un facteur de transcription activé par SREBP-1c, n'est pas modifiée par le gavage (Hérault et al 2010), alors qu'elle est accrue chez des rongeurs présentant une insulinorésistance et une stéatose hépatique (Browning et Horton 2004). Chez des oies landaises en fin de gavage, Zhu et al (2011) ont montré que plusieurs gènes impliqués dans la lipogenèse et la synthèse des triglycérides étaient surexprimés alors que des gènes impliqués dans la glycolyse, le métabolisme du cholestérol et l'oxydation des acides gras étaient sous-exprimés. Zhang et al (2013) ont confirmé, chez l'oie gavée, l'augmentation de l'expression de SCD dans le foie. L'accroissement du rapport ARN/ADN dans le foie traduit bien l'augmentation des synthèses protéiques à l'origine, d'une part des enzymes de la lipogenèse, et d'autre part, des synthèses membra- naires dues à l'hypertrophie cellulaire (Blum et Leclercq 1973). Une analyse du protéome hépatique réalisée à 3 stades de gavage $(0,14$ et 23 repas $)$ a mis en évidence des modifications d'expression de protéines pouvant être regroupées en 5 grandes catégories : enzymes, facteurs de transcription, structure cellulaire, antioxydants et liaison au calcium (Bax et al 2012). Par exemple, la protéine FAS impliquée dans la lipogenèse et la calpaïne, une protéase à cystéine dépendante du calcium intervenant dans la formation du cytosquelette mais également de l'apoptose cellulaire, sont surtout détectées en fin de gavage. L'augmentation de l'expression de deux facteurs de transcription impliqués dans la synthèse protéique, entre le début et le milieu du gavage, confirme l'anabolisme protéique important qui est mis en place lors de la première moitié du gavage. L'activité d'enzymes de la lipogenèse mesurée dans le foie chez des canards de Barbarie et mulard en fin de gavage est multipliée par 1,8 pour la glucose-6-phosphate déshydrogénase, par 4 pour l'enzyme malique et par 5 à 6 pour l'ACC, par rapport à des canards contemporains alimentés à volonté (tableau 1, Chartrin et al 2006a). En réponse au gavage, chez l'oie Landaise, la concentration plasmatique des VLDL et des HDL est multipliée respectivement par 2,9 et 2,3, (Hermier et al 1999a).
Chez le canard, la concentration du plasma en triglycérides, phospholipides et cholestérol est accrue (tableau 2, Baéza et al 2005). Cependant, cette sécrétion des lipides hépatiques est insuffisante pour empêcher l'accumulation de triglycérides dans les hépatocytes. D'une part, les capacités de synthèse de l'apo $\mathrm{B}$, protéine majeure des VLDL ou de la MTTP («Microsomal Triglyceride Transfer Protein ») qui permet l'assemblage des VLDL, pourraient être limitantes. D'autre part, les animaux sont en permanence sous l'effet d'une stimulation insulinique postprandiale (tableau 2) ce qui empêcherait les processus d'hydrolyse et de ré-estérification nécessaires à la mobilisation des triglycérides hépatiques. Cependant, en dépit de cette hyperinsulinémie, la glycémie reste plus élevée chez les animaux gavés (tableau 2). Toutefois, malgré un engraissement hépatique et corporel important il n'a jamais été mis en évidence de résistance à l'insuline chez les animaux gavés (Gontier et al 2013). Il faut remarquer que la période de gavage est relativement courte (12 jours) ce qui pourrait rendre difficile la mise en place de ce mécanisme. De plus, il semblerait que des adipocytokines (hormones sécrétées par le tissu adipeux) favorisant le développement d'une insulino-résistance chez les mammifères, telles que la leptine, la résistine, le PAI-1 («Plasminogen-Activator Inhibitor ») 
et le TNF- $\alpha$ («Tumor Necrosis Factor ») soient absentes chez les oiseaux (Pitel et al 2010, Monget et al 2013). Ceci pourrait expliquer, en partie, l'absence d'insulino-résistance chez les palmipèdes gavés. Par contre, les adipocytokines intervenant dans le phénomène d'insulinosensibilisation sont bien présentes chez les oiseaux, à l'exception de l'omentine (Monget et al 2013). Enfin, il faut rappeler que l'aliment de gavage est quasi exclusivement composé de grains de maïs. Or, le grain de maïs est faiblement pourvu en choline, acide folique et méthionine et ne contient pas de vitamine B12. Des études ont montré que des rats soumis à des régimes carencés en l'un ou plusieurs de ces composés présentaient des stéatoses hépatiques (Mc Neil et al 2008 et 2009, Kumar et al 2013). En effet, un apport insuffisant en donneurs de méthyle conduit à une augmentation de la teneur hépatique en homocystéine qui permet la surexpression de SREBP-1 favorisant la lipogenèse et donc la stéatose (Roblin et al 2007). Il serait intéressant d'étudier, chez les palmipèdes gavés, l'implication éventuelle du métabolisme des folates et de la méthionine dans le développement de la stéatose hépatique. En effet, la diminution du ratio PhosphatidylCholine/ PhosphatidylEthanolamine (PC/PE) observée par Molee et al (2005) dans la composition des phospholipides membranaires des hépatocytes de canards gavés a déjà été mise en évidence chez des rats soumis à des régimes carencés en choline (Mato et al 2008) et pourrait suggérer une implication du métabolisme des donneurs de méthyle dans la formation du foie gras. En effet, la PE est convertie en PC via trois N-méthylations successives ce qui nécessite la présence de donneurs de groupements méthyles (Mato et al 2008).

En résumé, le développement de la stéatose hépatique chez les palmipèdes est donc favorisé par différents mécanismes. Le foie est le principal site de synthèse des lipides. La capacité d'exportation des lipides hépatiques néo-synthétisés serait insuffisante au regard de la capacité de synthèse. La capacité de stockage des lipides circulants par les tissus périphériques serait elle aussi insuffisante, ce qui favoriserait un retour au foie d'une partie de ces lipides. La durée de gavage relativement courte et l'absence chez les oiseaux de plusieurs adipocytokines impliquées dans les phénomènes d'insulino-résistance pourraient expliquer l'absence de mise en place de ce mécanisme chez les palmipèdes gavés, contrairement à ce qui est couramment observé chez les mammifères atteints de stéatose hépatique. Le maïs utilisé pour le gavage, du fait de la quantité distribuée et de sa composition (riche en amidon et carencé ou faiblement pourvu en composés donneurs de groupements méthyles), stimule également la lipogenèse hépatique.

\section{3 / Cinétique de formation du foie gras}

a) Evolution du poids et de la composition chimique

Le poids du foie s'accroît régulièrement avec le nombre de repas de gavage (figure 2). Il en est de même pour le poids des différents constituants. En réponse au gavage, le foie stocke tout d'abord du glycogène dont la quantité est multipliée par 3 après 3 jours de gavage (figure 2, Baudonnet-Lenfant 1993). Toutefois, la progression la plus importante concerne les triglycérides dont la teneur passe de 1 à $53 \%$ au détriment de la teneur en eau qui décroît de 68 à $32 \%$ et de la teneur en protéines qui passe de 16 à $6 \%$ après 12 jours de gavage. En fin de gavage, les triglycérides représentent la fraction largement majoritaire des lipides totaux (environ 90\%). Ces triglycérides sont riches en Acides Gras Mono-Insaturés (AGMI), en particulier l'acide oléique, mais contiennent très peu d'Acides Gras Poly-Insaturés (AGPI) qui appartiennent quasi exclusivement à la série n-6 (Baudonnet-Lenfant 1993, tableau 3). La composition des lipides membranaires des hépatocytes est également modifiée par le gavage. Les teneurs en cholestérol et phospholipides membranaires sont multipliées par 1,5 (Molee et al 2005), mais le ratio cholestérol/phospholipides n'est pas affecté. Au sein des phospholipides membranaires, la teneur en phosphatidyléthanolamine est accrue au détriment de celle en phosphatidylcholine ce qui pourrait modifier la fluidité membranaire. La proportion d'acide oléique et d'acides gras n-9 augmente au détriment de celle en AGPI n-6 et n-3 (Molee et al 2005).

\section{b) Aspects cellulaires}

Lors d'un gavage bien conduit, les lésions macroscopiques sont normalement inexistantes et un foie de bonne qualité ne présente ni hémorragie, ni zone de nécrose ou d'inflammation, ni tâche verdâtre (cholestase). La trame conjonctive, réduite chez les oiseaux, est distendue à l'extrême, mais la capsule de Glisson qui entoure le foie, reste intacte. La surcharge lipidique ne concerne que les hépatocytes qui font l'objet d'une hypertrophie cellulaire (Labie et Tournut 1970). Il ne semble pas y avoir d'hyperplasie cellulaire (Bénard et Labie 1998). L'infiltration lipidique débute en zone périportale pour gagner progressivement l'espace centrolobulaire (Labie et Tournut 1970, Bénard et Labie 1998). En début de gavage, les lipides stockés dans le cytoplasme forment des microvacuoles qui ensuite grossissent pour for-

Figure 2. Evolution de la composition chimique du foie au cours du gavage de canards de Barbarie ( $n=10$, Baudonnet-Lenfant 1993).

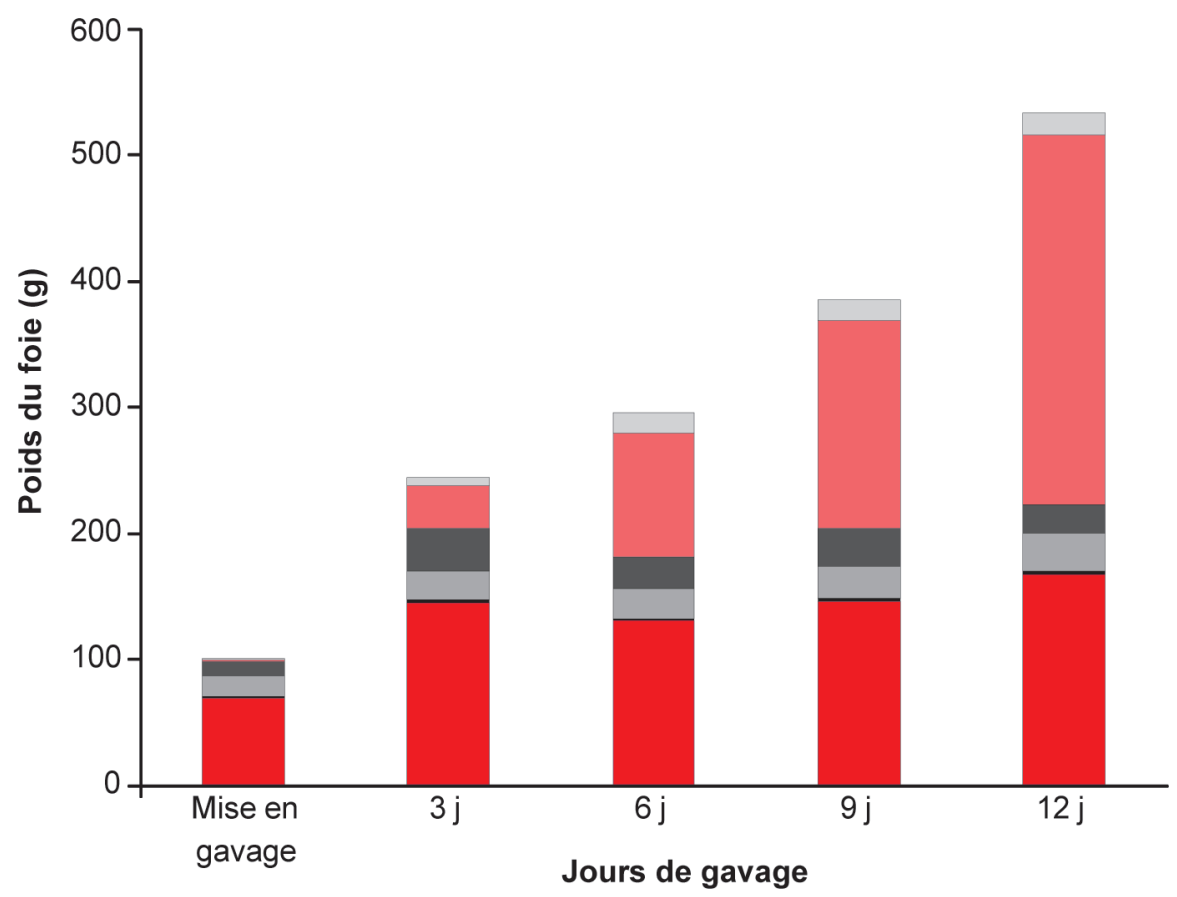

Eau $\square$ Minéraux $\square$ Protéines $\square \begin{aligned} & \text { Glycogène }+ \\ & \text { autres constituants }\end{aligned}$

Mono, di et triglycérides

+ acides gras libres
Phospholipides + cholestérol 
Tableau 3. Evolution du profil des acides gras totaux du foie (\%) au cours du gavage ( $n=9$, Baudonnet-Lenfant 1993).

\begin{tabular}{|c|c|c|c|c|c|}
\hline & \multicolumn{5}{|c|}{ Stades de gavage (jours) } \\
\hline & 0 & 3 & 6 & 9 & 12 \\
\hline C12:0 & nd & $0,06^{a}$ & $0,06^{a}$ & $0,07^{\mathrm{ab}}$ & $0,08^{b}$ \\
\hline C14:0 & $0,43^{a}$ & $1,32^{b}$ & $1,60^{c}$ & $1,54^{\mathrm{c}}$ & $1,52^{c}$ \\
\hline C16:0 & $32,65^{b}$ & $38,82 \mathrm{c}$ & $31,66^{b}$ & $31,69^{b}$ & $29,73^{a}$ \\
\hline C17:0 & $0,17^{a}$ & $0,05^{b}$ & nd & nd & nd \\
\hline C18:0 & $22,18^{\mathrm{C}}$ & $8,99^{a}$ & $15,18^{b}$ & $15,80^{b}$ & $15,52^{b}$ \\
\hline C20:0 & $0,24^{b c}$ & $0,07^{a}$ & $0,23^{c}$ & $0,13^{\mathrm{ab}}$ & $0,20^{b c}$ \\
\hline AGS & $55,67^{b}$ & $49,31^{a}$ & $48,73^{\mathrm{a}}$ & $49,23^{\mathrm{a}}$ & $47,05^{\mathrm{a}}$ \\
\hline C14:1 n-5 & $0,13^{a}$ & $0,22^{b}$ & $0,25^{\mathrm{b}}$ & $0,18^{a b}$ & $0,21^{\mathrm{b}}$ \\
\hline C16:1 n-7 & $1,24^{\mathrm{a}}$ & $7,64^{\mathrm{c}}$ & $5,41^{\mathrm{b}}$ & $4,72^{b}$ & $4,59^{b}$ \\
\hline C18:1 n-9 & $22,10^{\mathrm{a}}$ & $39,94^{\mathrm{b}}$ & $42,85^{\mathrm{C}}$ & $43,42^{\mathrm{C}}$ & $45,74^{d}$ \\
\hline $\mathrm{C} 20: 1 \mathrm{n}-9$ & nd & nd & $0,73^{a}$ & $0,70^{\mathrm{a}}$ & $0,86^{b}$ \\
\hline AGMI & $23,47^{\mathrm{a}}$ & $47,80^{b}$ & $49,24^{b c}$ & $49,02^{b c}$ & $51,40^{\mathrm{C}}$ \\
\hline C18:2 n-6 & $19,84^{d}$ & $2,85^{\mathrm{C}}$ & $1,93 b$ & $1,65^{b}$ & $1,44^{a}$ \\
\hline C18:3n-3 & $0,54^{\mathrm{C}}$ & $0,06^{a}$ & $0,09 a b$ & $0,08^{a b}$ & $0,11^{b}$ \\
\hline AGPI & $20,38^{c}$ & $2,91^{b}$ & $2,02^{\mathrm{ab}}$ & $1,73^{\mathrm{a}}$ & $1,55^{\mathrm{a}}$ \\
\hline
\end{tabular}

a, b, c : effet significatif du stade de gavage à $P<0,001$; nd : non détecté AGS, AGMI, AGPI : Acides Gras Saturés, Mono et Polylnsaturés.

mer en fin de gavage des macro-vacuoles occupant tout l'espace (Locsmandi et al 2007).

\section{4 / Réversibilité de la stéatose hépatique}

Comme indiqué précédemment, la stéatose hépatique est un phénomène réversible. Chez le canard mulard, trois durées de gavage $(10,13$ et 16 jours), permettant une production de foie gras de 333,530 et $636 \mathrm{~g}$ respectivement, ont été mises en place (Babilé et al 1996). A l'issue de chaque stade, des canards sont relâchés en élevage. Les premiers jours, la prise alimentaire est nulle, mais les animaux boivent abondamment. Plus le gavage a été long et plus la reprise de la consommation alimentaire est tardive (8 à 15 jours). Les pertes de poids vif sont très rapides lors de la première semaine. Le foie retrouve progressive- composition chimique entre les foies des deux lots.

La fréquence assez faible de signes d'inflammation hépatique (nécrose cellulaire et fibrose dues à des peroxydations lipidiques et du stress oxydant) lors du gavage des palmipèdes pourrait s'expliquer, en partie, par l'absence chez les oiseaux d'adipocytokines qui sont secrétées chez les mammifères par le tissu adipeux, telles que le PAI-1 et le TNF- $\alpha$ (Monget et al 2013) et qui jouent un rôle pro-inflammatoire notamment dans les cas de stéato-hépatites développées par des patients atteints de NAFLD ("Non Alcoholic Fatty Liver Disease ») ou de NASH («nonalcoholic steatohepatitis », Puppala et al 2013). Cette particularité des oiseaux pourrait favoriser la conservation de la fonctionnalité métabolique du foie lors du gavage et le caractère réversible de la stéatose hépatique chez les palmipèdes.

\section{2 / Déterminisme physiolo- gique de l'aptitude à la stéa- tose hépatique}

Les palmipèdes sont les seuls oiseaux domestiques gavés pour la production de foie gras et parmi eux, l'intensité de la stéatose hépatique varie en fonction des espèces. En France, la production commerciale du foie gras repose sur l'oie (Anser anser) de race Landaise, le canard mâle de Barbarie (Cairina moschata) et, surtout, sur le canard mâle mulard, hybride intergénérique de la cane commune de type Pékin (Anas plathyrynchos) et du canard de Barbarie. Les autres types d'oies ou de canards développent des stéatoses hépatiques réduites. Plusieurs études ont donc été réalisées pour rechercher les mécanismes expliquant ces différences d'aptitude à la stéatose hépatique entre espèces de palmipèdes.

aprè son poids initial (environ $80 \mathrm{~g}$ ) après 15 jours de relâchement pour les lots gavés pendant 10 et 13 jours et après 30 jours pour le lot gavé pendant 16 jours. Les analyses chimiques hépatiques et plasmatiques et les observations histologiques du foie confirment le retour progressif au stade physiologique et métabolique initial. Des canards mulards ont même été soumis à trois cycles de gavagedégavage successifs (Bénard et al 1998) et le retour à la situation physiologique initiale s'effectue en quatre semaines après l'arrêt du gavage. De plus, après le troisième gavage, le foie de canard ne présente aucun signe pathologique.

De même, des oies de 15 semaines, gavées pendant 18 jours, ont été relâchées en élevage et comparées à des oies contemporaines alimentées à volonté (Babilé et al 1998). Après 58 jours, il n'y a plus de différence de poids et de

\section{1 / Oies}

L'aptitude à la stéatose hépatique a été évaluée chez l'oie landaise par comparaison avec l'oie polonaise normalement élevée pour la production de viande (figure 3, Hermier et al 1999a) et avec l'oie italienne (Poujardieu et al 1994). En réponse au gavage, l'oie landaise développe un foie gras deux fois plus lourd que l'oie polonaise et ce malgré des quantités similaires d'aliment ingéré produire du foie gras. A l'inverse, l'engraissement périphérique (gras abdominal et sous-cutané) est plus prononcé chez l'oie polonaise que pour les 2 autres génotypes d'oie. En fin de gavage, chez les oies polonaises, l'activité de l'Enzyme Malique (EM) dans le foie est significaen gavage. L'oie italienne est inapte à 
Figure 3. Effet de la souche d'oie sur l'aptitude à la stéatose hépatique.

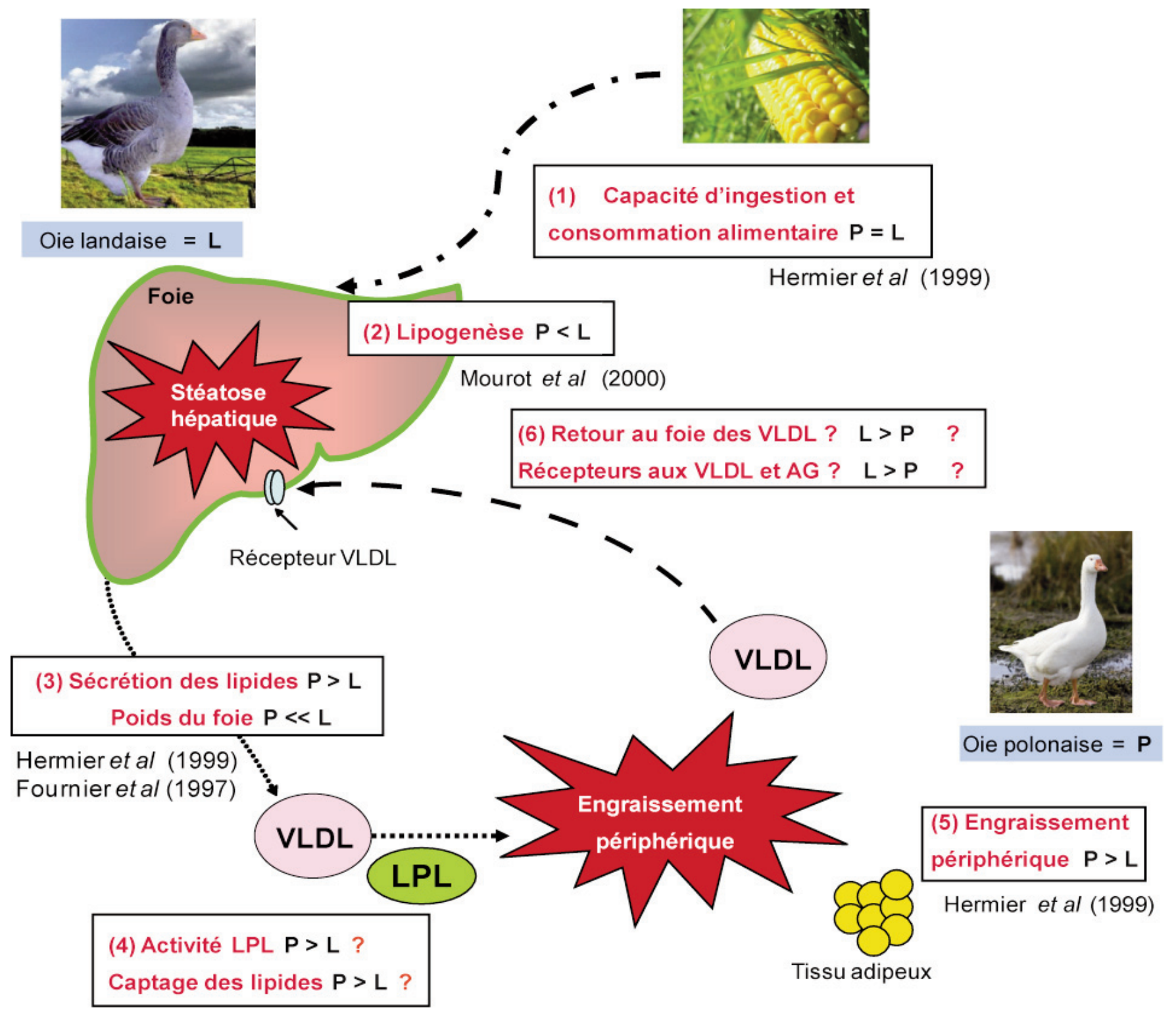

LPL : Lipoprotéine Lipase ; VLDL : Very Low Density Lipoproteins ; AG : Acides Gras.

tivement plus faible que chez les oies landaises. La stéatose hépatique serait donc limitée par la fourniture de NADPH pour cette souche car, par ailleurs, les activités enzymatiques de G6PDH (glucose-6- phosphate déshydrogénase), $\mathrm{ACC}$ et FAS sont équivalentes (figure 4, Mourot et al 2000). Une étude plus récente (Mourot et al 2006) a montré que les activités enzymatiques de EM, G6PDH et ACC dans le foie étaient plus importantes chez les oies landaises comparées aux oies polonaises. En fin de gavage, les oies polonaises ont des teneurs plasmatiques pour les différentes lipoprotéines, les triglycérides, les phospholipides et le cholestérol libre plus élevées que les oies landaises (Fournier et al 1997). De l'analyse de la composition en lipides et en acides gras des différentes lipoprotéines, il ressort que l'oie landaise présente un défaut d'incor- poration des triglycérides dans les VLDL (Fournier et al 1997) et un défaut d'incorporation de la phosphatidylcholine et des AGPI dans les HDL ce qui va favoriser la croissance des membranes des hépatocytes et faciliter leur hypertrophie (Hermier et al 1999b). La production supérieure de foie gras chez l'oie landaise serait donc due à une lipogenèse hépatique plus efficace et à une moindre capacité de sécrétion des lipides néosynthétisés. Toutefois, ce modèle mériterait des études complémentaires en particulier pour évaluer le rôle de l'insuline, la capacité de captage des lipides circulants par les tissus périphériques et quantifier la fraction des lipides circulants retournant au foie (figure 3 ).

\section{2 / Canards}

L'aptitude à la stéatose hépatique a été évaluée chez les deux espèces paren- tales du canard mulard, le canard de Barbarie et le canard Pékin (figure 5, Baéza et al 2005). En réponse au gavage, le canard de Barbarie développe un foie gras deux fois plus lourd que le canard Pékin et ce malgré des quantités similaires d'aliment ingéré en gavage. Le canard mulard qui consomme $25 \%$ d'aliment en plus que ses espèces parentales produit un foie gras à peine supérieur à celui du canard de Barbarie (Guy et al 1999). A l'inverse, l'engraissement périphérique (gras abdominal, sous-cutané et intramusculaire) est plus prononcé chez le canard Pékin. Le poids de foie plus élevé chez les canards de Barbarie et mulards s'explique par une accumulation plus importante de lipides et en particulier de triglycérides (Chartrin et al 2006b). En fin de gavage, l'activité enzymatique de ACC et FAS (figure 4) est plus importante dans le foie du canard de Barbarie que celle mesurée chez le canard Pékin. 
Figure 4. Mécanismes de la lipogenèse.

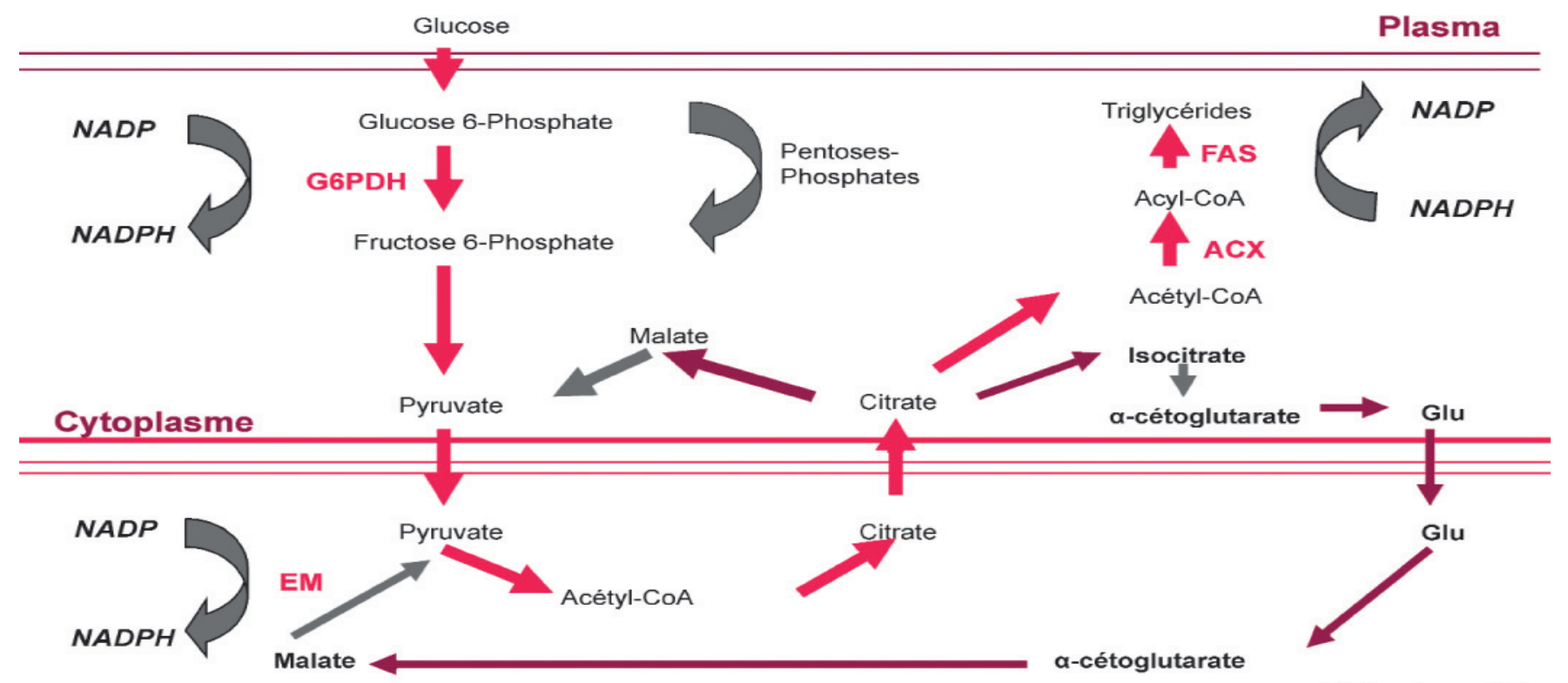

Mitochondrie

G6PDH : Glucose-6-Phosphate Déshydrogénase ; EM : Enzyme Malique ; NADP : Nicotinamide Adénine Dinucléotide Phosphate ; ACX : Acetyl Coa-Carboxylase.

Figure 5. Effet de l'espèce de canard sur l'aptitude à la stéatose hépatique.

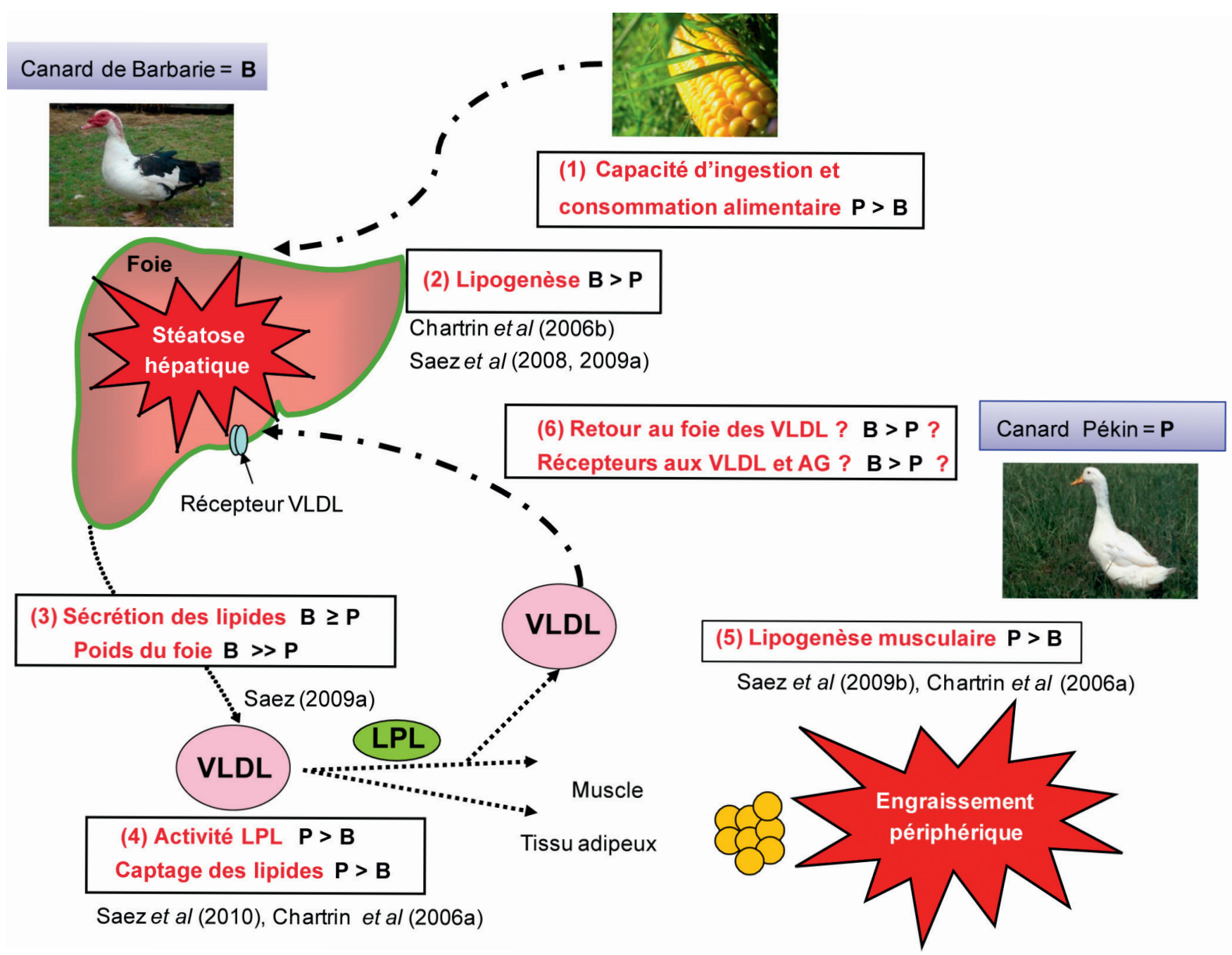

LPL : Lipoprotéine Lipase ; VLDL : Very Low Density Lipoproteins ; AG : Acides Gras. 
En revanche, pour G6PDH et EM c'est la situation inverse qui est observée. Chez des animaux nourris à volonté, Saez et al (2009a) ont démontré que la capacité de synthèse et de stockage hépatique de lipides est supérieure chez le canard de Barbarie ce qui pourrait expliquer, en partie, sa meilleure aptitude à la production de foie gras. En fin de gavage, l'expression de ChREBP dans le foie est plus importante chez le canard de Barbarie alors que l'expression de SREBP-1c est équivalente chez les deux espèces (figure 1, Hérault et al 2010). L'expression de la FAS est également supérieure chez le canard de Barbarie alors que celle de SCD-1, DGAT2, apo B et CPT1A sont inférieures suggérant pour le canard de Barbarie une activité de lipogenèse hépatique plus importante, mais un défaut d'assemblage des triglycérides et des lipoprotéines ainsi qu'une diminution de l'oxydation des acides gras. Selon le niveau d'alimentation (canards nourris à volonté ou gavés pendant une semaine), la sécrétion hépatique de lipides sous forme de VLDL est soit supérieure chez le canard de Barbarie par rapport au canard Pékin, soit équivalente pour les deux espèces (Saez et al 2008 et 2009a). Néanmoins, le canard Pékin semblerait plus apte à limiter la stéatose hépatique en sécrétant des VLDL plus riches en triglycérides (Saez et al 2012). Par ailleurs, la teneur plasmatique en phospholipides, cholestérol et triglycérides et lipoprotéines est plus élevée chez les canards Pékin (Baéza et al 2005). En revanche, la glycémie est plus importante chez le canard de Barbarie. Pour l'insulinémie, il est plus difficile de conclure car ce paramètre a été mesuré soit chez des animaux à jeun montrant un niveau équivalent chez les deux espèces, soit chez des animaux nourris, mais dans ce dernier cas, il n'est pas certain que la cinétique d'évolution post prandiale soit la même pour les deux espèces. Le captage musculaire des lipides circulants (activité de la lipoprotéine lipase supérieure) et la capacité de stockage intramusculaire des lipides sont plus importants chez le canard Pékin (Chartrin et al 2006a, Saez et al 2010). La lipogenèse musculaire, bien que très faible par comparaison avec la lipogenèse hépatique, est également plus active chez le canard Pékin (Saez et al 2009b). L'ensemble de ces mécanismes permettrait d'expliquer l'engraissement périphérique plus important du canard Pékin et probablement un moindre retour des lipides circulants vers le foie limitant ainsi le développement de la stéatose hépatique chez cette espèce.

Sans que les mécanismes physiologiques de la stéatose aient été explorés, le type génétique de la cane commune (Pékin, Tsaiya Brune ou les hybrides Pékin $\times$ Tsaiya / Tsaiya $\times$ Pékin) mère du mulard, influence aussi l'aptitude à la stéatose de celui-ci. Ainsi, le poids de foie produit par les canards mulards issus de canes Pékin est bien supérieur à celui des canards mulards issus de canes Tsaiya (respectivement 641 et $441 \mathrm{~g}$ ), les hybrides ayant une position intermédiaire (Rouvier et al 1994). Du fait des différences importantes de gabarit adulte entre la cane Pékin ( $3 \mathrm{~kg}$ ) et la cane Tsaiya $(1,4 \mathrm{~kg})$, Brun et al (1995) ont étudié les répartitions lipidiques chez leurs fils mulards gavés en pourcentage du poids vif. Ils ont montré que les canards mulards issus de canes Tsaiya avaient une stéatose hépatique plus importante et des dépôts de gras périphériques (gras abdominal et sous cutané au niveau de la cuisse et du magret) plus faibles que les canards mulards issu de canes Pékin. Les canards mulards issus des deux hybrides étaient caractérisés d'une part, par une stéatose hépatique similaire à celle des canards mulards issus de canes Tsaiya et d'autre part, par un dépôt périphérique des lipides intermédiaire entre ceux des canards mulards issus des deux génotypes purs.

En définitive, l'aptitude à produire un foie gras dépendrait donc de plusieurs mécanismes : une lipogenèse hépatique très importante, une faible oxydation des lipides hépatiques, une capacité d'exportation des lipides néo-synthétisés (synthèse des lipoprotéines et assemblage des lipides à ces lipoprotéines) par le foie insuffisante au regard de la quantité de lipides néo-synthétisés et un captage limité des lipides circulants par les tissus périphériques permettant leur retour vers le foie. La sélection des palmipèdes sur leur capacité à produire du foie gras a probablement accentué une partie ou l'ensemble de ces mécanismes.

\section{3 / Déterminisme génétique de l'aptitude à la stéatose hépatique}

La sélection génétique de l'aptitude à la stéatose hépatique, telle que pratiquée par les sélectionneurs, ne se limite actuellement qu'à la prise en compte du poids de foie gras. Néanmoins, cette sélection nécessite de connaitre le déterminisme génétique des principaux caractères impliqués dans la stéatose. D'une part, l'héritabilité du poids de foie gras et ses corrélations génétiques avec tous les autres caractères d'intérêt doit être estimée pour apprécier l'évolution du poids de foie selon l'effort de sélection pratiqué, mais aussi les changements induits indirectement sur les autres caractères. D'autre part, l'effet d'hétérosis (différence entre la performance moyenne des hybrides et celle des parents) doit être quantifié, particulièrement chez le mulard, afin de choisir les souches parenta- les les plus adaptées au croisement. Ces approches de génétique quantitative classique seront complétées par la présentation des gènes impactant l'aptitude à la stéatose hépatique et identifiés grâce aux détections de QTL et aux études transcriptomiques et protéomiques.

\section{1 / Paramètres génétiques de la production de foie gras}

Peu d'études ont analysé les paramètres du croisement (tel que l'effet d'hétérosis) sur le poids de foie gras. Chez l'oie landaise, le croisement de souches sélectionnées n'a pas permis d'observer un effet d'hétérosis significatif sur le poids de foie gras (Rouvier et al 1992). En revanche, lors d'un croisement factoriel entre une souche de canard de Barbarie et une souche de canard Pékin, le poids de foie gras (en valeur brute et en pourcentage du poids vif de l'animal) bénéficie d'un fort effet d'hétérosis $(+150 \mathrm{~g})$, et d'un effet maternel favorable de la cane commune (Larzul et al 2006) : le mulard profite donc d'une complémentarité des effets d'hétérosis et maternel pour le foie gras, d'où une stéatose hépatique supérieure à celle du meilleur parent (MarieEtancelin et al 2008).

Une synthèse des valeurs d'héritabilités et de corrélations génétiques des caractères liés à la stéatose est présentée dans le tableau 4. La sélection directe du poids de foie gras dans des populations d'oies (grises landaises ou blanches d'Italie) et de canard de Barbarie est efficace, avec des valeurs d'héritabilité estimées entre 0,52 et 0,58 pour les oies (Larzul et al 2000, Richard et al 2006) et entre 0,20 et 0,40 (Fernandez 1988, Babilé 1989, Mignon-Grasteau et al 1998) pour les canards de Barbarie. De plus, Larzul et al (2000) ont montré que chez l'oie blanche d'Italie, le gras abdominal (lui aussi très héritable : 0,49 ) présente une corrélation génétique faible mais favorable $(-0,10)$ avec le poids de foie gras. Aucune démonstration n'a été faite que la sélection du canard de Barbarie sur sa propre aptitude à la stéatose influence favorablement celle de son fils mulard. L'amélioration génétique de ces caractères de stéatose chez le canard mulard s'effectue donc par sélection des lignées parentes (soit la lignée paternelle de Barbarie - Cairina moschata -, soit la lignée maternelle commune - Anas plathyrynchos -, ou les deux lignées) à partir des performances des descendants mulards (Marie-Etancelin et al 2008). La sélection du poids de foie gras du canard mulard est donc plus complexe et conduit à des valeurs d'estimations plus faibles qu'en population pure, par exemple en population de canards de Barbarie (Marie-Etancelin et al 2011). Ainsi, l'héritabilité du poids de foie du canard mulard gavé dans la lignée maternelle 
Tableau 4. Héritabilités de caractères qualifiant la stéatose hépatique et corrélations génétiques avec le poids de foie estimées chez différentes espèces.

\begin{tabular}{|c|c|c|c|c|c|}
\hline & Caractères & Oie & $\begin{array}{c}\text { Canard de } \\
\text { Barbarie }\end{array}$ & $\begin{array}{l}\text { Canard mulard } \\
\text { (lignée commune) }\end{array}$ & $\begin{array}{l}\text { Canard mulard } \\
\text { (lignée Barbarie) }\end{array}$ \\
\hline \multirow{6}{*}{$h^{2}$} & Poids de foie & $\begin{array}{l}0,52^{(\mathrm{e})} \\
0,58^{(\mathrm{g})}\end{array}$ & $\begin{array}{l}0,20^{(\mathrm{b})} \\
0,39^{(\mathrm{d})} \\
0,40^{(\mathrm{a})}\end{array}$ & $\begin{array}{l}0,05^{(\mathrm{h})} \\
0,10^{(\mathrm{f})} \\
0,17^{(\mathrm{c})} \\
0,18^{(\mathrm{i})}\end{array}$ & $\begin{array}{l}0,04^{(\mathrm{h})} \\
0,09^{(\mathrm{i})}\end{array}$ \\
\hline & Gras abdominal & $0,49^{(\mathrm{e})}$ & & $0,25^{(\mathrm{i})}$ & $0,09^{(i)}$ \\
\hline & Peau du magret & & & $0,16^{(\mathrm{i})}$ & $0,10^{(i)}$ \\
\hline & Glucose * & & & $0,12^{(i)}$ & $0,06^{(i)}$ \\
\hline & Cholestérol total * & & & $0,12^{(i)}$ & $0,03^{(i)}$ \\
\hline & Triglycérides * & & & $0,13^{(i)}$ & $0,03^{(i)}$ \\
\hline \multirow{2}{*}{$\begin{array}{l}r_{g} \\
\text { du } \\
\text { PF }\end{array}$} & Gras abdominal & $-0,10^{(\mathrm{e})}$ & & $+0,03^{(i)}$ & $+0,39^{(i)}$ \\
\hline & Peau du magret & & & $-0,29^{(i)}$ & $+0,41^{(i)}$ \\
\hline
\end{tabular}

* Paramètres sanguins mesurés en fin de gavage $; h^{2}:$ Coefficient d'héritabilité $; r_{g}$ : Coefficient de corrélation génétique ; PF : Poids de Foie.

${ }^{(a)}$ Fernandez 1988, (b) Babilé 1989n ${ }^{(\mathrm{c})}$ Poujardieu et al 1994, ${ }^{(\mathrm{d})}$ Mignon-Grasteau et al 1998, (e) Larzul et al 2000,

(f) Larzul 2002, ${ }^{(\mathrm{g})}$ Richard et al 2006, ${ }^{(\mathrm{h})}$ Chapuis et Larzul 2008, ${ }^{(\mathrm{i})}$ Marie-Etancelin et al 2011.

commune varie entre 0,05 et 0,18 selon les auteurs (Chapuis et Larzul 2008, Marie-Etancelin et al 2011), les estimations les plus élevées étant obtenues à partir de lots d'animaux expérimentaux. Toujours dans la lignée commune, l'héritabilité du gras de la peau des magrets du canard mulard est de l'ordre de 0,16 tandis que celle du gras abdominal s'élève à 0,25 avec d'une part, une indépendance génétique entre poids de foie et gras abdominal et, d'autre part, une faible corrélation (de - 0,06 à - 0,29) entre poids de foie et gras de la peau des magrets (Marie-Etancelin et al 2011). Enfin, si des marqueurs sanguins du métabolisme énergétique du canard mulard (taux de glucose, de cholestérol et de triglycérides) sont héritables en fin de gavage dans la population commune $(0,12)$, ils semblent génétiquement sans lien avec les caractères de la stéatose hépatique (Marie-Etancelin, communication personnelle). Dans la lignée paternelle Barbarie, l'héritabilité du poids de foie du mulard gavé varie entre 0,04 et 0,09, ce qui est très proche des estimations d'héritabilités pour le gras de la peau des magrets et le gras abdominal (environ 0,10 ) et bien plus faible que les estimations obtenues dans la lignée maternelle commune (Chapuis et Larzul 2008, Marie-Etancelin et al 2011). Les corrélations génétiques entre ces trois caractères sont différentes de celles estimées dans la lignée maternelle : chez le canard de Barbarie, Marie-Etancelin et al (2011) estiment que le poids de foie gras du mulard est corrélé génétiquement avec le gras abdominal et le gras sous-cutané de la peau des magrets $(+0,41$ et $+0,39$, respectivement).
En résumé, quelle que soit l'espèce, le poids du foie gras et le gras abdominal sont des caractères efficacement sélectionnables, avec pour le mulard un déterminisme génétique plus important dans la lignée maternelle que dans la lignée paternelle. La sélection du poids de foie gras génère des réponses différentes selon les espèces, notamment sur le gras abdominal et la peau des magrets.

\section{2 / Mise en évidence de QTL pour la production de foie gras}

A notre connaissance, seule une étude a porté sur la recherche de zones chromosomiques à effet quantitatif (QTL pour " Quantitative Trait Locus ») sur la stéatose hépatique (Kileh-Wais et al 2013). L'objectif de ce dispositif expérimental était d'identifier des QTL dans le génome de la cane commune s'exprimant chez son fils mulard. Ainsi, trois QTL, significatifs au seuil de $1 \%$ au niveau du chromosome et agissant sur le poids de foie gras du canard mulard, ont été détectés sur les chromosomes 2, 9 et 21 de la cane commune. De façon surprenante, aucun QTL n'a été identifié concernant les caractères d'engraissement périphérique que sont le gras abdominal et le gras de la peau des magrets. Enfin, plusieurs QTL moins significatifs (seuil de $5 \%$ au niveau du chromosome) pour des marqueurs sanguins du métabolisme énergétique (taux de glucose, de cholestérol et de triglycérides) ont été localisés sur les chromosomes 2, 3, 6, 14, 21, 28 et $\mathrm{Z}$. Aucun lien, via une recherche de QTL pleïotropiques, n'a pu être fait entre les marqueurs sanguins et les différents compartiments de dépôts lipidiques (foie, gras abdominal et gras de la peau des magrets).

\section{3 / Analyse du transcriptome par séquençage de l'ARN}

Jusqu'à très récemment, le développement d'outils d'analyse à haut-débit de l'expression des gènes chez le canard a été gravement handicapé par l'absence de séquence de référence. Seules quelques rares études ont été publiées, faisant appel à une puce comportant 2912 amplicons différents de canard commun (Huang et al 2011a) ou à une puce commerciale dédiée au poulet pour une étude plus large (Huang et al 2011b). Cependant, le développement récent de nouvelles technologies de séquençage permet maintenant de s'affranchir de cette contrainte et autorise l'analyse à haut débit de l'expression des gènes (cf. Vignal et al 2013, ce numéro). Les travaux faisant appel à ces méthodes de séquençage de nouvelle génération sont toutefois encore très rares chez le canard. Le travail développé par Li et al (2012) concerne l'analyse des gènes impliqués dans la formation des plumages noirs et blancs. En ce qui nous concerne, nous avons entrepris un projet de séquençage d'ARNs à haut débit directement en relation avec le développement de la stéatose hépatique. Il vise à analyser le transcriptome hépatique de deux espèces de canards (Pékin et Barbarie) et de leurs produits hybrides (mulard et hinny), tous placés sous deux statuts nutritionnels : gavés et nourris ad libitum. Une fois aboutis, ces travaux devraient apporter de précieux indices sur les mécanismes impliqués dans les différences d'aptitude 
à la stéatose hépatique observées entre ces différents génotypes (Diot et al 2013).

\section{4 / Engraissement spontané du foie chez les palmipèdes}

En période pré-migratoire, les oies sauvages sont capables de s'engraisser fortement (Raveling 1978 et 1979). Leur poids vif peut être multiplié par 1,5 avec une augmentation de la proportion de graisse corporelle pouvant atteindre $209 \%$. Dans ce cas, le poids de foie est doublé et la teneur en lipides hépatiques est multipliée par 5. La diminution de la durée du jour et probablement aussi de la température favoriserait un accroissement de la consommation d'aliment et donc de dépôt de graisses corporelles chez l'oie préparée pour la migration hivernale (Raveling 1979 , Bairlein et Gwinner 1994). A partir de ces observations, Guy et al (2013) ont testé la possibilité d'obtenir un engraissement spontané d'oies landaises âgées de 19 semaines, alimentées à volonté avec du maïs après une période de rationnement et soumises à une photopériode décroissante (de 10 à $7 \mathrm{~h}$ de lumière entre les âges de 21 et 23 semaines). Au cours des 2 premières semaines suivant le rationnement, les oies ont consommé en moyenne $600 \mathrm{~g}$ de maïs par jour. Cette consommation a ensuite diminué progressivement pour atteindre $270 \mathrm{~g}$ à l'âge de 31 semaines. Le poids du foie a aug- menté de $95 \mathrm{~g}$ à 19 semaines à $514 \mathrm{~g}$ à 31 semaines, avec une augmentation en parallèle de la teneur en lipides représentant de 6 à $50 \%$ du poids du foie confirmée par l'analyse histologique. Cette étude a bien démontré qu'avec des conditions d'élevage et d'alimentation adaptées, les oies sont capables d'initier une stéatose hépatique spontanée sans présenter de signes d'altération tissulaire. Toutefois, dans ces conditions, la variabilité de réponse des oies est très importante (coefficient de variation du poids de foie de $45 \%$ à 31 semaines). Les recherches sur cette thématique doivent donc être poursuivies pour déterminer les origines de cette variabilité et essayer de la réduire.

\section{Conclusion}

L'aptitude à la stéatose hépatique de certaines espèces voire souches de palmipèdes est exploitée depuis des milliers d'années pour produire du foie gras. Toutefois, l'essor de cette production en France est relativement récent. Elle a pratiquement doublé au cours des vingt dernières années passant de 9730 tonnes en 1994 (OFIVAL 1999) à 19189 tonnes en 2012 (CIFOG 2013). Ce fort accroissement a été permis grâce à différents facteurs comme l'augmentation de la taille et de la productivité des ateliers de gavage, l'amélioration des outils et des techniques de production (automatisation des gaveuses, logement en cages indivi- duelles qui seront prochainement toutes remplacées par des cages collectives, maîtrise des conditions d'ambiance, composition et modalités de présentation de l'aliment de gavage, diminution de la durée de gavage...) et la sélection des canards parentaux sur les performances de gavage de leurs descendants mulards. Il existe encore des marges de progrès. Les connaissances en cours d'acquisition sur le déterminisme génétique de l'aptitude au gavage devraient permettre d'envisager à plus ou moins long terme une sélection assistée par marqueur ou par génotypage direct des reproducteurs des espèces parentales, ce qui économiserait le testage sur les descendants mulards. Sélectionner les individus les plus aptes à produire du foie gras devrait permettre d'envisager aussi une diminution de la durée du gavage et de la variabilité de réponse au gavage limitant ainsi les risques de mortalité en gavage et améliorant la qualité des foies gras. La préparation des animaux au gavage peut encore être améliorée en explorant, par exemple, les possibilités de programmation métabolique précoce et les processus d'épigénétique comme décrit par Brun et al (2013), qui ont testé l'influence du taux de méthionine dans l'aliment de la cane commune sur les performances de gavage des descendants mulards. Ces travaux devraient approfondir nos connaissances des voies métaboliques impliquées dans les processus de stéatose hépatique chez les palmipèdes.

\section{Références}

Babilé R., 1989. La production de foies gras de canards de Barbarie (Caïrina moschata) : Aspects génétiques, nutritionnels et technologiques. Thèse de Doctorat, INP Toulouse, France, $231 \mathrm{p}$.

Babilé R., Auvergne A., Andrade V., Héraut F., Bénard G., Bouillier-Oudot M., Manse H., 1996. Réversibilité de la stéatose hépatique chez le canard mulard. $2^{\text {èmes }}$ Journ. Rech. Palmipèdes à foie gras, Bordeaux, France, 107-110.

Babilé R., Auvergne A., Dubois J.P., Bénard G., Manse H., 1998. Réversibilité de la stéatose hépatique chez l'oie. $3^{\text {emes }}$ Journ. Rech. Palmipèdes à foie gras, Bordeaux, France, 45-48.

Baéza E., Rideau N., Chartrin P., Davail S., Hoo-Paris R., Mourot J., Guy G., Bernadet M.D., Juin H., Meteau K., Hermier D., 2005. Canards de Barbarie, Pékin et leurs hybrides : aptitude à l'engraissement. INRA Prod. Anim., $18,131-141$

Bairlein F., Gwinner E., 1994. Nutritional mechanisms and temporal control of migratory energy accumulation in birds. Ann. Rev. Nutr., $14,187-215$

Baudonnet-Lenfant C., 1993. Facteurs de variation de la composition biochimique et de la qualité technologique des foies gras de canards. Thèse de Doctorat, INP, Toulouse, France, 182p.

Bax M.L., Chambon C., Marty-Gasset N., Rémignon H., Fernandez X., Molette C., 2012. Proteomic profile evolution during steatosis development in ducks. Poult. Sci., 91, 112-120.

Bénard G., Labie C., 1998. Evolution histologique du foie des palmipèdes au cours du gavage. $3^{\text {emes }}$ Journ. Rech. Palmipèdes à Foie Gras, Bordeaux, France, 31-36.

Bénard G., Bénard P., Prehn D., Bengone T., Jouglar J.Y., Durand S., 1998. Démonstration de la réversibilité de la stéatose hépatique obtenue par gavage de canards mulards. Etude réalisée sur trois cycles de gavage-dégavage. $3^{\text {imes }}$ Journ. Rech. Palmipèdes à Foie Gras, Bordeaux, France, 49-52.

Blum J.C., Leclercq B., 1973. Nouvelles précisions sur les modifications biochimiques et histologiques du foie provoquées par le gavage. Atti delle Giornate Avicole, Varese, Italie, 31, 193-207.

Browning J.D., Horton J.D., 2004. Molecular mediators of hepatic steatosis and liver injury. J. Clin. Invest., 114, 147-152.

Brun J.M., Guy G., Poujardieu B., RousselotPailley D., Rouvier R., 1995. Composition ana- tomique de canards mulards mâles de 4 génotypes : influence de l'âge et du gavage. Ann. Zootech., 44, 281-295.

Brun J.M., Basso B., Bernadet M.D., Cornuez A., Leroux S., Lessire M., Dellier N., Pitel F., Morrisson M., 2013. Influence du taux de méthionine dans l'aliment de la cane commune sur les performances de gavage de ses descendants mulards : une question de programmation métabolique précoce et d'épigénétique ? $10^{\text {emes }}$ Journ. Rech. Palmipèdes à Foie Gras, La Rochelle, France, 730-733.

CIFOG, 2013. Rapport économique de l'année 2012. Assemblée Générale du CIFOG, 21/06/13, Sarlat, France, 82p.

Chapuis H., Larzul C., 2008. Comment estimer simultanément les paramètres génétiques des caractères de gavage dans les 2 lignées parentales du mulard en vue d'une sélection plus efficace? Journ. Rech. Palmipèdes à Foie Gras, Arcachon, France, 29-32.

Chartrin P., Bernadet M.D., Guy G., Mourot J., Hocquette J.F., Rideau N., Duclos M.J., Baéza E., 2006a. Does overfeeding enhance genotype effects on energy metabolism and lipid deposition in breast muscle of ducks? Comp. Biochem. Physiol., Part A, 145, 413-418. 
Chartrin P., Bernadet M.D., Guy G., Mourot J., Hocquette J.F., Rideau N., Duclos M.J., Baéza E., 2006b. Does overfeeding enhance genotype effects on liver ability for lipogenesis and lipid secretion in ducks? Comp. Biochem. Physiol., Part A, 145, 390-396.

Diot C., Houée-Bigot M., Demeure O., Baéza E., Vignal A., Pitel F., Marie-Etancelin C., Robert-Granié C., Molette C., Bouchez O. Esquerré D., Marsaud N., Klopp C., Peterlongo P., Lemaitre C., 2013. Analyse de transcriptomes de foies de canards par séquençage d'ARN (RNA-SEQ). 10 $0^{\text {èmes }}$ Journ. Rech. Avicole et Palmipèdes à Foie Gras, La Rochelle, France, 562-565.

Fernandez X., 1988. Etude de la variabilité génétique d'une population de canards de Barbarie mâles sur les caractères de croissance et de gavage de ses descendants. Mémoire de fin d'étude, Ecole Nationale Supérieure Agronomique de Toulouse, France, 50p.

Fournier E., Peresson R., Guy G., Hermier D., 1997. Relationships between storage and secretion of hepatic lipids in two breeds of geese with different susceptibility to liver steatosis. Poult. Sci., 76, 599-607.

Gontier K., André J.M., Bernadet M.D., Ricaud K., Davail S., 2013. Insulin effect on lipogenesis and fat distribution in three genotypes of ducks during overfeeding. Comp. Biochem. Physiol., A164, 499-505.

Guy G., Hermier D., Davail S., Bely M., André J.M., Hoo-Paris R., 1999. Meat production and force-feeding ability of different types of ducks. In: $1^{\text {st }}$ World Waterfowl Conf., 1-4/12/99, Taichung, Taiwan, 462-468.

Guy G., Fortun-Lamothe L., Bénard G., Fernandez X., 2013. Natural induction of spontaneous liver steatosis in Greylag Landaise geese (Anser anser). J. Anim. Sci., 91, 455-464.

Hérault F., Saez G., Robert E., Al Mohammad A., Davail S., Chartrin P., Baéza E., Diot C., 2010. Liver gene expression in relation to hepatic steatosis and lipid secretion in two duck species. Anim. Genet., 41, 12-20.

Hermier D., Forgez P., Laplaud P.M., Chapman M.J., 1988. Density distribution and physicochemical properties of plasma lipoproteins in the goose, Anser anser, a potential of liver steatosis. J. Lipid Res., 29, 893-907.

Hermier D., Salichon M.R., Guy G., Peresson R., Mourot J., Lagarrigue S., 1999a. La stéatose hépatique des palmipèdes gavés : bases métaboliques et sensibilité génétique. In : Numéro spécial, Lipogenèse et qualité des produits. Chilliard Y. (Ed). INRA Prod. Anim., $12,265-271$

Hermier D., Salichon M.R., Guy G., Peresson R., 1999b. Differential channelling of liver lipids in relation to susceptibility to hepatic steatosis in the goose. Poult. Sci., 78, 13981406.

Huang H.L., Cheng Y.S., Huang C.W., Huang M.C., Hsu W.H., 2011a. A novel genetic marker of the ovomucoid gene associated with hatchability in Tsaiya ducks (Anas platyrhynchos). Anim. Genet., 42, 421-427.

Huang H.L., Cheng Y.S., Yang K.T., Chen C.H., Huang M.C., Hsu W.H., 2011b. Genomewide transcript expression analysis in the uterovaginal junction in association with fertile period in Tsaiya ducks. J. Reprod. Dev., 57, 731-736.

Kileh-Wais M., Elsen J.M., Vignal A., Feves K., Vignoles F., Fernandez X., Manse H.,
Davail S., André J.M., Bastianelli D., Bonnal L., Filangi O., Baéza E., Guémené D., Genet C., Bernadet M.D., Dubos F., Marie-Etancelin C., 2013. Detection of QTL controlling metabolism, meat quality, and liver quality traits of the overfed interspecific hybrid mule duck. J. Anim. Sci., 91, 588-604.

Kumar K.A., Lalitha A., Pavithra D. Padmavathi I.J.N., Ganeshan M., Rao K.R., Venu L., Balakrishna N., Shanker N.H., Reddy S.U., Chandak G.R., Sengupta S., Raghunath M., 2013. Maternal dietary folate and/or vitamin $\mathrm{B} 12$ restrictions alter body composition (adiposity) and lipid metabolism in Wistar rat offspring. J. Nutr. Biochem., 24, 25-31.

Labie C., Tournut B., 1970. Recherches sur les modifications histologiques et biochimiques chez les oies soumises au gavage. Cah. Med. Vet., 39, 247-261.

Larzul C., Rouvier R., Rousselot-Pailley D., Guy G., 2000. Estimation of genetic parameters for growth, carcass and overfeeding traits in a white geese strain. Genet. Select. Evol., 32, 415-427.

Larzul C., 2002. Paramètres génétiques du gavage. $5^{\text {emes }}$ Journ. Rech. Palmipèdes à Foie Gras, Pau, France, 33-36.

Larzul C., Imbert B., Bernadet M.D., Guy G., Rémignon H., 2006. Meat quality in an intergeneric factorial crossbreeding between Muscovy (Cairina moschata) and Pekin (Anas platyrhyncos) ducks. Anim. Res., 55, 1-11.

Léveille G.A., Romsos D.R., Yeh Y.Y., O'Hea E.K., 1975. Lipid biosynthesis in the chick. A consideration of the site of synthesis, influence of diet and possible regulatory mechanisms. Poult. Sci., 54, 1075-1093.

Li S., Wang C., Yu W., Zhao S., Gong Y., 2012. Identification of genes related to white and black plumage formation by RNA-Seq from white and black feather bulbs in ducks. PLoS One, 7, e36592.

Locsmandi L., Hegedüs G., Andrassy-Baka G., Bogenfürst F., Romvari R., 2007. Following the goose liver development by means of crosssectional digital imaging, liver histology and blood biochemical parameters. Acta Biol. Hungarica, 58, 35-78.

Marie-Etancelin C., Chapuis H., Brun J.M., Larzul C., Richard M.M., Rouvier R., 2008. Genetics and selection of mule ducks in France: A review. World's Poult. Sci. J., 64, 187-207.

Marie-Etancelin C., Basso B., Davail S. Gontier K., Fernandez X., Vitezica Z.G., Bastianelli D., Baéza E., Bernadet M.D., Guy G., Brun J.M., Legarra A., 2011. Genetic parameters of product quality and hepatic metabolism in fattened mule ducks. J. Anim. Sci., 89, 669-79.

Mato J.M., Martinez-Chantar M.L., Lu S.C. 2008. Methionine metabolism and liver disease. Ann. Rev. Nutr., 28, 273-293.

Mc Neil C.J., Hay S.M., Rucklidge G.J. Reid M.D., Duncan G.J., Malonye C.A., Rees W.D., 2008. Disruption of lipid metabolism in the liver of the pregnant rat fed folate deficient and methyl donor-deficient diets. Br. J. Nutr., 99, 262-271.

Mc Neil C.J., Hay S.M., Rucklidge G.J., Reid M.D., Duncan G.J., Rees W.D., 2009 Maternal diets deficient in folic acid and related methyl donors modify mechanisms associated with lipid metabolism in the fetal liver of the rat. Br. J. Nutr., 102, 1445-1452.
Mignon-Grasteau S., Beaumont C., Poivez J.P., de Rochambeau H., 1998. Estimation of the genetic parameters of sexual dimorphism of body weight in 'label' chickens and Muscovy ducks. Genet. Select. Evol., 30, 481-491.

Molee W., Bouillier-Oudot M., Auvergne A., Babilé R., 2005. Changes in lipid composition of hepatocyte plasma membrane induced by overfeeding in duck. Comp. Biochem. Physiol. B141, 437-444.

Monget P., Dupont J., Baéza E., Pitel F., Lagarrigue S., Gondret F., 2013. Spécificités évolutives du métabolisme des lipides chez le poulet. $10^{\text {èmes }}$ Journ. Rech. Avicoles et Palmipèdes à Foie Gras, La Rochelle, France, 720-724.

Mourot J., Guy G., Lagarrigue S., Peiniau P., Hermier D., 2000. Role of hepatic lipogenesis in the susceptibility to fatty liver in the goose (Anser anser). Comp. Biochem. Physiol., B126, 81-87.

Mourot J., Guy G., Peiniau P., Hermier D., 2006. Effects of overfeeding on lipid synthesis, transport and storage in two breeds of geese differing in their capacity for fatty liver production. Anim. Res. 55, 427-442.

OFIVAL, 1999. Le marché des produits carnés et avicoles en 1999, 432p

Pingel H., Guy G., Baéza E., 2012. Production de foie gras. In : Production de canards. Ed. Quae, Versailles, France, 197-210.

Pitel F., Faraut T., Bruneau G., Monget P., 2010. Is there a leptin gene in the chicken genome? Lessons from phylogenetics, bioinformatics and genomics. Gen. Comp. End. $167,1-5$.

Poujardieu B., Rouvier R., Rousselot-Pailley D., Guy G., Rosinski A., Wezyk S., 1994. Croissance et aptitude au gavage d'oies de 3 génotypes. Ann. Zootech., 43, 197-211.

Puppala J., Siddapuram S.P., Akka J., Munshi A., 2013. Genetics of nonalcoholic fatty liver disease: an overview. J. Genet. Genom., 40, 15-22.

Raveling D.G., 1978. The timing of egg laying by northern geese. Auk, 95, 294-303.

Raveling D.G., 1979. The annual cycle of body composition of Canada geese with special reference to control of nutrition. Auk, 96, 234252 .

Richard M.M., Marie-Etancelin C., Dubos F., Bernadet M.D., Guy G., Brun J.M., 2006. Genetic parameters of reproduction and forcefeeding traits in geese under artificial lighting conditions. $8^{\text {th }}$ World Cong. Appl. Livest. Prod., Instituto Prociencias Minas Gerais, Minas Gerais, Belo Horizonte, Brazil, 407425 .

Roblin X., Pofelski J., Zarski J.P., 2007. Rôle de l'homocystéine au cours de la stéatose hépatique et de l'hépatite chronique C. Gastroenterol. Clin. Biol., 31, 415-420.

Rouvier R., Poujardieu B., Rousselot-Pailley D., Larrue P., Esteve D., 1992. Paramètres génétiques des caractères de croissance, de gavage et de foie gras dans le croisement de deux souches d'oies (Anser anser) sélectionnées. Genet. Select. Evol., 24, 53-69.

Rouvier R., Guy G., Rousselot-Paillet D., Poujardieu B. 1994. Genetic parameters from factorial cross breeding in two duck strains (Anas platyrhynchos) Brown Tsaiya and Pekin, for growth and fatty liver traits. Br. Poult. Sci., $35,509-517$. 
Saez G., Baéza E., Davail S., Durand D., Bauchart D., Gruffat D., 2008. Is the hepatic metabolism of glucose and linoleic acid influenced by species in overfed ducks? Comp. Biochem. Physiol., Part A, 151, 576-581.

Saez G., Baéza E., Davail S., Durand D. Bauchart D., Gruffat D., 2009a. Hepatic metabolism of glucose and linoleic acid varies in relation to susceptibility to fatty liver in $a d$ libitum-fed Muscovy and Pekin ducks. Br. J. Nutr., 101, 502-509.

Saez G., Davail S., Gentes G., Hocquette J.F., Jourdan T., Degrace P., Baéza E., 2009b. Gene expression and protein content in relation to intramuscular fat content in Muscovy and Pekin ducks. Poult. Sci., 88, 2382-2391.

Saez G., Baéza E., Bernadet M.D., Davail S., 2010. Is there a relationship between the kinetics of lipoprotein lipase activity after a meal and the susceptibility to hepatic steatosis development in ducks? Poult. Sci., 89, 24532460

Saez G., Savary-Auzeloux I., Baéza E., Bernadet M.D., Davail S., Durand D., Bauchart D., Gruffat D., 2012. Fractional apoB-VLDL hepatic synthesis rate in Muscovy and Pekin ducks fed ad libitum. Arch. Geflugelk., 76, 2025.
Vignal A., Diot C., Molette C., Morisson M., Faraut T., Rao M., Pitel F., Fillon V., MarieEtancelin C., 2013. Génomique des canards. In : Palmipèdes à foie gras. Fortun-Lamothe L. (Ed). Dossier, INRA Prod. Anim., 26, 391-402.

Zhang R., Zhu L., Zhang Y., Shao D., Wang L., Gong D., 2013. cDNA cloning and the response to overfeeding in the expression of stearoyl-CoA desaturase 1 gene in Landes goose. Gene, 512, 464-469.

Zhu L.H., Meng H., Duan X.J., Xu G.Q., Zhang J., Gong D.Q., 2011. Gene expression profile in the liver tissue of geese after overfeeding. Poult. Sci., 90, 107-117.

\title{
Résumé
}

Le foie gras des palmipèdes gavés est l'expression d'une stéatose hépatique d'origine nutritionnelle, hypertrophique, réversible et caractérisée par une accumulation de triglycérides dans les hépatocytes. Cette aptitude est favorisée par certaines particularités physiologiques et métaboliques des oiseaux en particulier un site prépondérant de synthèse des lipides qui est le foie et l'utilisation d'un aliment spécifique, le maïs riche en amidon et distribué en grandes quantités aux palmipèdes. Cet apport important de maïs va activer deux facteurs de transcription, SREBP-1c et ChREBP régulés respectivement par l'insuline et par le glucose, et qui vont agir ensuite sur la glycolyse et la lipogenèse. Toutefois, l'aptitude à la production de foie gras varie selon les espèces voire les souches de palmipèdes. Elle repose, essentiellement, sur une capacité de lipogenèse hépatique accrue, une capacité de sécrétion hépatique des triglycérides néo-synthétisés insuffisante et une capacité de captage des lipides circulants par les tissus périphériques limitée favorisant ainsi leur retour vers le foie et accentuant le développement de la stéatose. La sélection sur le poids de foie gras est efficace. Trois QTL agissant sur le poids de foie gras du canard mulard, ont été détectés sur les chromosomes 2, 9 et 21 de la cane commune. Par ailleurs, avec des conditions d'élevage et d'alimentation adaptées, les oies sont capables d'initier une stéatose hépatique spontanée. Cela constitue une perspective pour développer une production de foie gras sans recours au gavage.

\begin{abstract}
Hepatic steatosis in waterfowl

The fatty liver of overfed waterfowl results from a hepatic steatosis induced by specific nutritional conditions. This steatosis is hypertrophic, reversible and characterised by an accumulation of triglycerides in the hepatocytes. This ability is favoured by different physiological and metabolic peculiarities of birds such as the main site of lipid synthesis which is the liver and the use of a specific feed, maize rich in starch and distributed in large quantities to waterfowl. This important amount of maize stimulates two transcription factors regulated respectively by insulin, SREBP-1c and by glucose, ChREBP which will act then on glycolysis and lipogenesis. However, the ability to produce fatty liver depends on species and even the genotype of waterfowl. It results essentially from an increased capacity of hepatic lipogenesis, an insufficient hepatic capacity to export neo synthesised triglycerides and a limited capacity of peripheral tissues in the uptake of circulating lipids then favouring their return towards the liver and therefore increasing the development of steatosis. The selection on the weight of fatty liver is effective. Three QTL controlling the weight of fatty liver of the mule duck were detected on chromosomes 2,9 and 21 of the common female duck. In addition with adapted rearing and feeding conditions, geese are able to initiate a spontaneous hepatic steatosis. This constitutes a perspective to developing fatty liver production without using overfeeding.
\end{abstract}

BAÉZA E., MARIE-ETANCELIN C., DAVAIL S., DIOT C., 2013. La stéatose hépatique chez les palmipèdes. In : Palmipèdes à foie gras. Fortun-Lamothe L. (Ed). Dossier, INRA Prod. Anim., 26, 403-414. 